\title{
The Dynamics of Oil Prices, Exchange Rates, and the Stock Market Under COVID-19 Uncertainty: Evidence From India
}

\author{
K.P. Prabheesh ${ }^{1}$ (D) ${ }^{a}$, Sanjiv Kumar ${ }^{1}$ (D) \\ ${ }^{1}$ Department of Liberal Arts, Indian Institute of Technology, Hyderabad, India \\ Keywords: svar, exchange rate, stock return, oil price, uncertainty \\ https://doi.org/10.46557/001c.27015
}

\section{Energy RESEARCH LETTERS}

Vol. 2, Issue 3, 2021

\begin{abstract}
This study empirically analyzes the dynamic relation between oil price returns, exchange rates, stock returns, and uncertainty shocks. Utilizing daily data, we employ a structural vector autoregression econometric technique to explore the impact of uncertainty in the Indian context. The study finds that COVID-19-induced uncertainty dampened the oil and stock markets. Further, findings suggest that COVID-19-induced uncertainty distorted the dynamics between oil and stock prices in the initial periods, due to the cautionary approach followed by investors.
\end{abstract}

\section{Introduction}

The COVID-19 outbreak and its subsequent spread across the world saw many countries adopt strict mitigating policies, such as lockdowns, domestic and international travel bans, and fiscal stimulus (Narayan, 2021). These policy responses created uncertainties for both investors and policymakers. The stock markets reacted differently, from an initial negative reaction to a reaction correction; that is, investors overreacted to the pandemic. Similarly, policymakers, given the growing uncertainty and lingering presence of the pandemic, have been uncertain about policy measures for recovery (Padhan \& Prabheesh, 2021).

Such persistent and growing uncertainty immediately affected the stock market (Haroon \& Rizvi, 2020), exchange rates (Iyke, 2020; Rai \& Garg, 2021), and trade and economic growth (Vidya \& Prabheesh, 2020). The oil market also experienced high turbulence due to the rise in uncertainty (Devpura \& Narayan, 2020; Narayan, 2020). A sharp reduction in oil consumption due to lockdowns led to a drastic decline in crude oil prices in the international market, from USD 61 on January 2, 2020, to USD 12 on April 28, 2020 . Since oil price movements play a key role in the performance of the foreign exchange and stock markets of oilimporting economies, as shown by Prabheesh et al. (2020), COVID-19-induced uncertainty could distort the dynamic interlinkages between oil prices, stock returns, and exchange rates. Thus, the present paper investigates whether and how these dynamic relations have evolved in the face of the COVID-19 pandemic.

The theoretical link between exchange rates and stock price movements with oil prices is abundantly discussed in the literature, where we seek motivation. The oil price-exchange rate nexus, for instance, states that a rise in oil price leads to depreciation of the currencies of importing economies and shifts the wealth from oil-importing to oilexporting countries (Salisu et al., 2021). Similarly, the nexus between oil prices and stock prices shows that a rise in oil price increases the cost of production and decreases economic growth, leading to a decline in stock prices due to lower future earnings and dividends (Narayan et al., 2014; Narayan \& Sharma, 2011).

The literature on uncertainty and market movements shows that an increase in macroeconomic and policy uncertainty negatively affects economic growth, which, in turn, reduces the demand for oil, as well as its price. Similarly, uncertainty is the key factor driving volatility in stock prices and exchange rates. There has been exponential growth in the COVID-19 literature from a business and economics perspective (for recent surveys, see Padhan \& Prabheesh, 2021 and Narayan, 2021). However, studies related to uncertainty that originated from the COVID-19 pandemic are scarce and mainly analyze the impact of COVID-19-based uncertainty on individual markets. They find that COVID-19 uncertainty has adversely affected oil prices and returns (Devpura \& Narayan, 2020), exchange rates (Rai \& Garg, 2021), and stock returns (Haroon \& Rizvi, 2020; Prabheesh et al., 2020; Rai \& Garg, 2021). However, none of these studies addresses the dynamics of the three markets in the presence of COVID-19 uncertainty, especially from the perspective of oil-importing economies.

The present study addresses this issue in the Indian context. We choose India because 1) India has been severely impacted by the COVID-19 crisis and 2) India is the sixth 
largest economy in the world and imports $96 \%$ of its total oil consumption. Thus, our study contributes to the literature in the following ways. First, our treatment of oil prices, exchange rates, and stock returns over the COVID-19 period represents the first analysis of the relation between these three policy-relevant variables. Second, we utilize the dataset constructed by Narayan, Iyke, et al. (2021) to examine the impact of uncertainty shock on the Indian economy, which makes this study unique and novel.

The remainder of the paper is organized as follows. Sections II and III present the data and empirical methodology, respectively. Section IV discusses the empirical findings and performs robustness checks. Finally, Section V concludes the paper.

\section{Data}

We obtain daily data from December 31, 2019, to April 28,2021 . Stock prices are obtained from the National Stock Exchange of India Limited and are proxied by the NIFTY 50 index. Similarly, the exchange rate between the Indian rupee (INR) and the US dollar (USD) is drawn from the China Economic Information Center database. The price of West Texas Intermediate is considered a proxy for the oil price, and its data are obtained from the U.S. Energy Information Administration's website (https://www.eia.gov). For the uncertainty index $(U I)$, we utilize the latest data, developed by Narayan, Iyke, et al. (2021). Both oil prices and stock prices are converted into returns, following the literature.

\section{Empirical Methodology}

This study utilizes a structural vector autoregression (SVAR) model to evaluate the relation between oil returns $(O R)$, computed as $\log \left(\frac{w t i}{w t i_{t-1}}\right) * 100$; the bilateral nominal INR-USD exchange rate $(E R)$; stock returns $(S R)$, calculated as $\log \left(\right.$ Stock$_{/}$Stock $\left._{t-1}\right) * 100$ and the uncertainty index UI. The model is of the following form:

$$
B_{0} Y_{t}=B_{1}(L) Y_{t}+C \epsilon_{t}
$$

where $Y_{t}$ symbolizes an $n \times 1$ vector of variables in time period $T ; B_{0}$ and $C$ represent $n \times n$ matrices of coefficients; $B_{1}(L)$ is a polynomial matrix that includes lag terms; matrix $C$ represents the structural parameters; and $\epsilon_{t}$ is an $n \times$ 1 vector of serially independent errors with a zero mean and an identity covariance matrix. The reduced-form version of the equation is

$$
Y_{t}=D(L) Y_{t}+v_{t}
$$

where $D(L) Y_{t}=\beta_{0}^{-1} \beta_{1}(L)$, with $\beta_{0} \nu_{t}=C \epsilon_{t}$. The term $\nu_{t}$ is the residual term of the reduced-form VAR model and presumed to follow a white noise error process; however, it can be related to other variables because of their contemporaneous effects across the system.

To identify shocks, appropriate restrictions are required.
We apply a short-run restriction on the contemporaneous coefficient of the matrix $\beta_{0}$. To precisely identify the structural shock, as a rule of thumb, we need to specifically impose $\left(n^{2}-n\right) / 2$ restrictions. The identification strategy of the model can be described as

$$
\begin{gathered}
Y_{t}=(O R, E R, S R, U I) \\
{\left[\begin{array}{rrrrr}
a_{11} & 0 & 0 & 0 \\
a_{21} & a_{22} & 0 & 0 \\
a_{31} & a_{32} & a_{33} & 0 \\
a_{41} & a_{42} & a_{43} & a_{44}
\end{array}\right]\left[\begin{array}{c}
u_{t,}^{O R} \\
u_{t}^{E R} \\
u_{t}^{S R} \\
u_{t}^{U I}
\end{array}\right]} \\
=\left[\begin{array}{ccccc}
b_{11} & 0 & 0 & 0 & 0 \\
0 & b_{22} & 0 & 0 & 0 \\
0 & 0 & b_{33} & 0 & 0 \\
0 & 0 & 0 & b_{44} & 0
\end{array}\right]\left[\begin{array}{c}
u_{t}^{O R} \\
u_{t}^{E R} \\
u_{t}^{S R} \\
u_{t}^{U I}
\end{array}\right]
\end{gathered}
$$

For the identification strategy, we presume that the $O R$ values are contemporaneously exogenous to all the variables in the model. The evidence of Narayan et al. (2014) suggests that oil prices are exogenous for most countries, including India. The $E R$ variable is presumed to be endogenous to $O R$ and contemporaneously exogenous to $S R$ and $U I$, and $S R$ is presumed to be endogenous to $O R$ and $E R$ and exogenous to $U I$. Lastly, $U I$ is assumed to be endogenous to all the variables in the model.

To determine the dynamics of the variables in the system, we utilize structural impulse response functions and structural variance decomposition (SVD). The impulse response function helps discern the response of the variable in the event of shocks in the other variables in the model. SVD allows us to obtain the exact percentage of forecast error explained by the innovation terms of all the variables in the system.

\section{Empirical Findings}

As a preliminary step, we check the stationarity of the variables. ${ }^{1}$ Next, to estimate the SVAR, we select 16 lags and use the Akaike information criteria. Figure 1 depicts the impulse responses of $O R$ to a positive shock to the system. We can see that $O R$ responds negatively to an unexpected shock in UI. The effect is statistically significant for at least two days after the shock. This finding implies that COVID-19-associated uncertainty dampens $O R$. These findings are in line with those of Devpura \& Narayan (2020), Narayan (2020), and Narayan, Phan, et al. (2021), who argue that COVID-19 has had a significant negative impact on the oil market. We also observe that $O R$ responds negatively to a positive shock to $E R$ (depreciation). However, the response of $E R$ is insensitive to any of the shocks in the system. The insensitivity of $E R$ during the period of the pandemic could be attributed to the active intervention of the Reserve Bank of India (India's central bank) in the foreign exchange market by selling USD from its international reserves. ${ }^{2}$

\footnotetext{
1 We do not report the findings of the unit root due to space constraints. Our findings show that all the variables are stationary, except for the exchange rate and the uncertainty index. We convert the nonstationary variables into their stationary form.

2 The Reserve Bank of India’s foreign reserves dropped from USD 485.818 billion to USD 477.450 billion from February 28, 2020, to May 1,
} 
2020 (data from the China Economic Information Center). See also https://www.ideasforindia.in. 
Response to Structural One S.D. Innovations \pm 2 S.E.

Response of OR to $D(E X)$

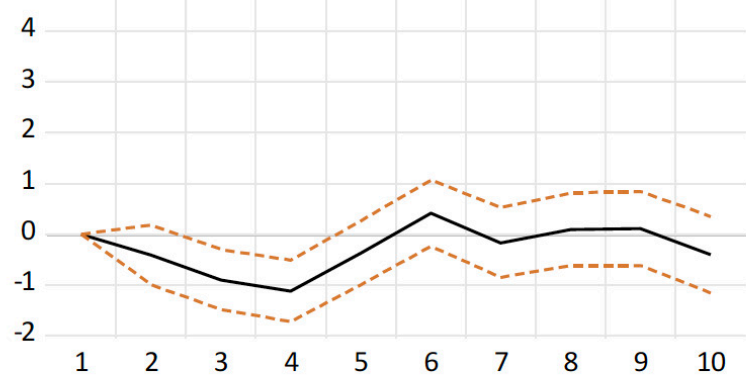

Response of $D(E R)$ to $O R$

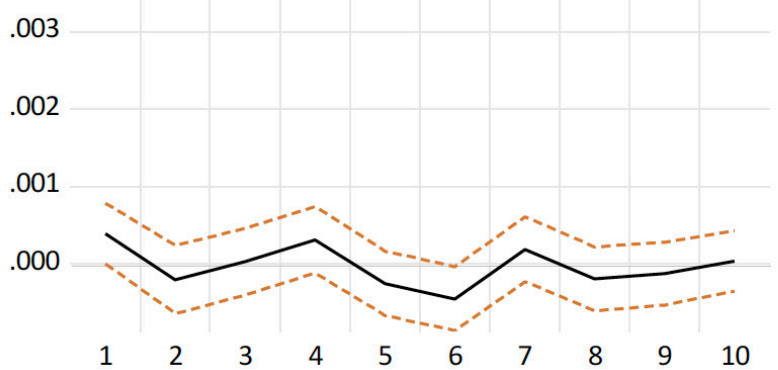

Response of SR to OR

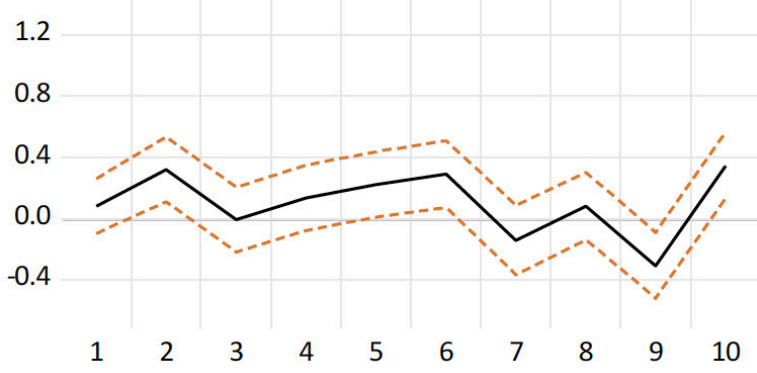

Response of OR to SR

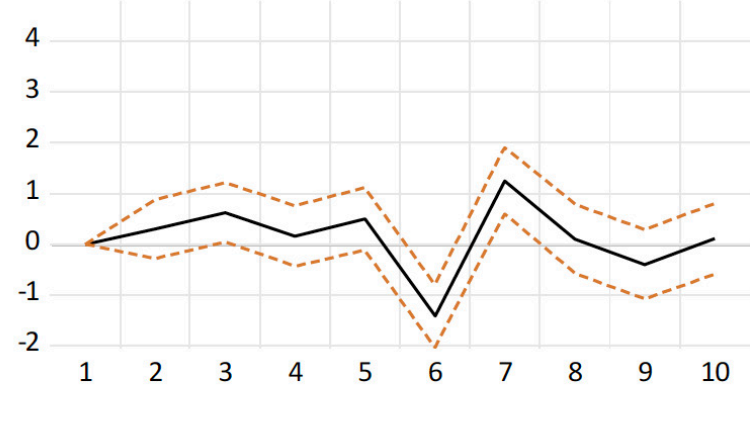

Response of $\mathrm{D}(\mathrm{ER})$ to Shock3

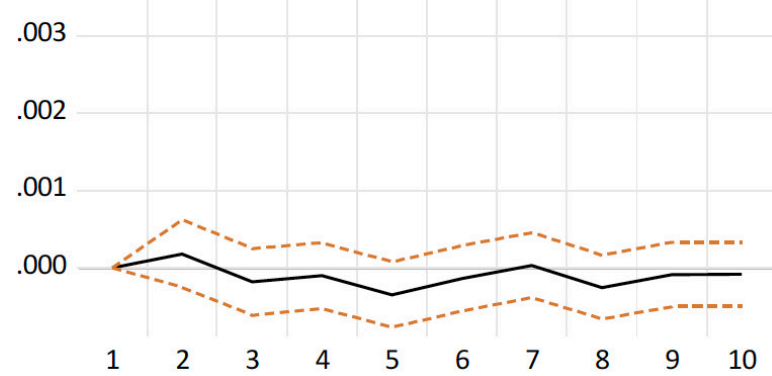

Response of SR to D(EX)

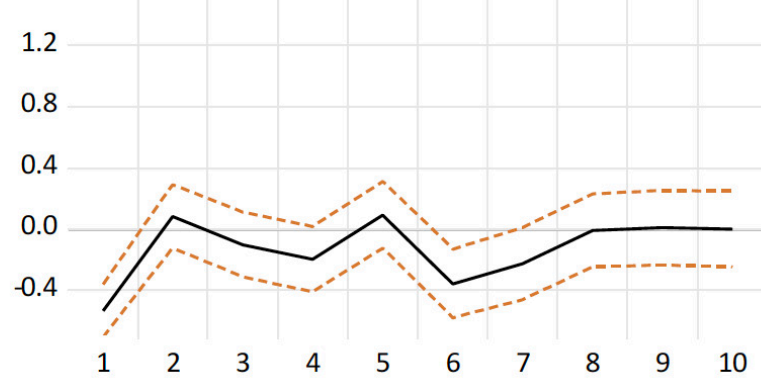

Response of OR to $\mathrm{D}(\mathrm{UI})$

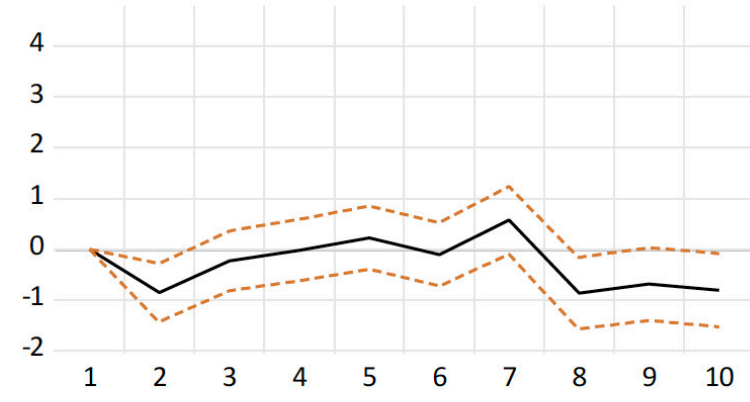

Response of $D(E R)$ to $D(U I)$
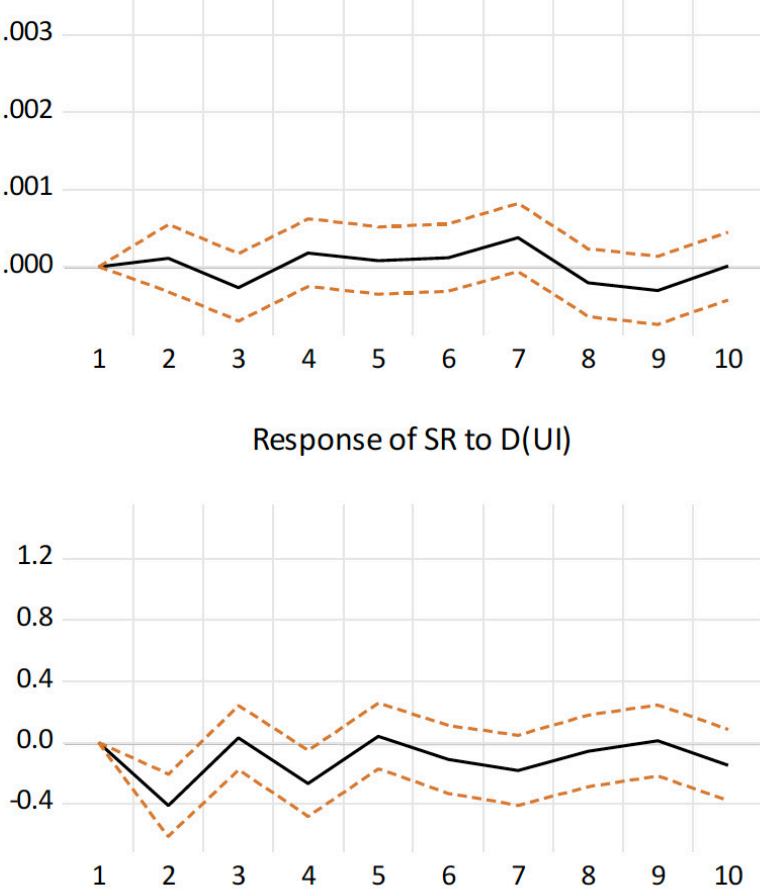

\section{Figure 1. Structural Impulse Response Function}

This figure shows the impulse response function derived from the SVAR model. The term, $O R$, represents oil returns, $E X$ is the nominal exchange rate (INR/USD), $S R$ is stock returns (NIFTY-50), and UI is the uncertainty index. The SVAR model includes $O R, E X, S R, U I$. 
Table 1. Structural Variance Decomposition

\begin{tabular}{|c|c|c|c|c|}
\hline \multicolumn{5}{|c|}{ Structural Variance decomposition of $O R$} \\
\hline Day & OR & $E R$ & $S R$ & UI \\
\hline 1 & 100.000 & 0.000 & 0.000 & 0.000 \\
\hline 5 & 85.082 & 8.746 & 3.184 & 2.988 \\
\hline 10 & 71.934 & 7.497 & 13.522 & 7.046 \\
\hline \multicolumn{5}{|c|}{ Structural Variance decomposition of $E R$} \\
\hline & OR & $E R$ & $S R$ & UI \\
\hline 1 & 1.481 & 98.519 & 0.000 & 0.000 \\
\hline 5 & 3.106 & 94.194 & 1.694 & 1.005 \\
\hline 10 & 5.091 & 89.163 & 2.389 & 3.358 \\
\hline \multicolumn{5}{|c|}{ Structural variance decomposition of $S R$} \\
\hline & OR & $E R$ & $S R$ & UI \\
\hline 1 & 0.294 & 12.209 & 87.497 & 0.000 \\
\hline 5 & 5.338 & 11.406 & 75.517 & 7.739 \\
\hline 10 & 12.875 & 13.853 & 65.726 & 7.547 \\
\hline
\end{tabular}

This table presents the structural variance decomposition of $O R, E R, S R$ and $U I$. The structural variance decompositions are reported for days 1,5 and 10 . The SVAR model includes $O R, E R, S R, U I$.

Figure 1 also shows the response of $S R$. The response of $S R$ to $O R$ is found to be positive on the second day and negative from the sixth day onward. The lagged negative response could be due to investors' cautionary approach during the COVID-19 pandemic period. This weak relation between $O R$ and $S R$ indicates that COVID-19-induced uncertainty distorted the relation between the two markets in the initial days of the shock. Similarly, the response of $S R$ to $E R$ is found to be negative and statistically significant in the initial days. This result shows that depreciation of the domestic currency leads to a decline in $S R$; that is, it reduces foreign investors' returns in the Indian stock market, who therefore sell Indian stocks to protect their portfolios. Our study's results are in line with those of Rai \& Garg (2021). Finally, we also observe that uncertainty reduces domestic stock returns, $S R$. Our overall findings suggest that COVID-19-induced uncertainty dampened the oil and stock markets, but not the exchange market.

Further, COVID-19-induced uncertainty distorted the relation between the oil market and the stock market initially. Table 1 shows the SVD of $O R, E R$, and SR. In most cases, variations in the variables are largely explained by their own innovation. It is important to note that $U I$ explains variations in $O R$ and $S R$ of around $7 \%$ and $7.5 \%$, respectively. In the case of $E R$, by comparison, $U I$ accounts for only $3.3 \%$ of the forecast error variance. These findings imply that the exchange market is less affected by
COVID-19-induced uncertainty than the stock and oil markets. We also observe that around $13.5 \%$ of the variation in $O R$ is explained by variation in $S R$ during the 10th day. Similarly, around $12.8 \%(13.8 \%)$ of the variation in $S R$ is explained by $O R(E R)$ during the same period.

For a robustness check, we utilize the Chicago Board Options Exchange Volatility Index as a proxy for uncertainty (drawn from https://fred.stlouisfed.org) and re-estimate the SVAR. The overall responses of the variables are similar to our previous findings, and we thus conclude that our results are not sensitive to the alternative uncertainty measures. Detailed results are available upon request.

\section{Conclusions}

COVID-19-induced uncertainty had a significant negative impact on the global financial markets. This paper examines the dynamic relation between the three most important markets, namely, the oil market, the foreign exchange market, and the stock market, in the presence of uncertainty associated with COVID-19 in the Indian context. Our empirical findings show that COVID-19-induced uncertainty dampened the oil and stock markets, but not the foreign exchange market. This is likely due to the Reserve Bank of India's active intervention. Finally, our findings suggest that COVID-19-induced uncertainty distorted the dynamics between oil prices and stock prices in the initial periods due to the cautionary approach of investors. 


\section{REFERENCES}

Devpura, N., \& Narayan, P. K. (2020). Hourly oil price volatility: The role of COVID-19. Energy Research Letters, 1(2), 13683.

Haroon, O., \& Rizvi, S. A. R. (2020). COVID-19: Media coverage and financial markets behavior-A sectoral inquiry. Journal of Behavioral and Experimental Finance, 27, 100343. https://doi.org/10.1016/j.jbef.202 0.100343

Iyke, B. N. (2020). The disease outbreak channel of exchange rate return predictability: Evidence from COVID-19. Emerging Markets Finance and Trade, 56(10), 2277-2297. https://doi.org/10.1080/1540496 х.2020.1784718

Narayan, P. K. (2020). Oil price news and COVID-19-Is there any connection? Energy Research Letters, 1(1), 13176. https://doi.org/10.46557/001c.13176

Narayan, P. K. (2021). COVID-19 research outcomes: An agenda for future research. Economic Analysis and Policy, 71, 439-445. https://doi.org/10.1016/j.eap.202 $\underline{1.06 .006}$

Narayan, P. K., Iyke, B. N., \& Sharma, S. S. (2021). New Measures of the COVID-19 Pandemic: A New TimeSeries Dataset. Asian Economics Letters, 2(2), 23491.

Narayan, P. K., Phan, D. H. B., \& Liu, G. (2021). COVID-19 lockdowns, stimulus packages, travel bans, and stock returns. Finance Research Letters, 38, 101732. https://doi.org/10.1016/j.frl.2020.101732

Narayan, P. K., Sharma, S., Poon, W. C., \& Westerlund, J. (2014). Do oil prices predict economic growth? New global evidence. Energy Economics, 41, 137-146. http s://doi.org/10.1016/j.eneco.2013.11.003
Narayan, P. K., \& Sharma, S. S. (2011). New evidence on oil price and firm returns. Journal of Banking \& Finance, 35(12), 3253-3262. https://doi.org/10.1016/ j.jbankfin.2011.05.010

Padhan, R., \& Prabheesh, K. P. (2021). The economics of COVID-19 pandemic: A survey. Economic Analysis and Policy, 70, 220-237. https://doi.org/10.1016/i.eap.202 1.02.012

Prabheesh, K. P., Padhan, R., \& Garg, B. (2020). COVID-19 and the oil price-stock market nexus: Evidence from net oil-importing countries. Energy Research Letters, 1(2), 13745. https://doi.org/10.4655 7/001c. 13745

Rai, K., \& Garg, B. (2021). Dynamic correlations and volatility spillovers between stock price and exchange rate in BRIICS economies: Evidence from the COVID-19 outbreak period. Applied Economics Letters, 1-8. https://doi.org/10.1080/13504851.2021.1884835

Salisu, A. A., Cuñado, J., Isah, K., \& Gupta, R. (2021). Oil Price and Exchange Rate Behaviour of the BRICS. Emerging Markets Finance and Trade, 57(7), 2042-2051. https://doi.org/10.1080/1540496x.2020.1 $\underline{850440}$

Vidya, C. T., \& Prabheesh, K. P. (2020). Implications of COVID-19 pandemic on the global trade networks. Emerging Markets Finance and Trade, 56(10), 2408-2421. https://doi.org/10.1080/1540496x.2020.1 $\underline{785426}$ 